\title{
EXPERIMENTAL PERFORMANCE OF PV FED LED LIGHTING SYSTEM EMPLOYING PARTICLE SWARM OPTIMIZATION (PSO)
}

\author{
B. Venkatesh Reddy ${ }^{1}$, D. Giri Babu ${ }^{2}$ \\ ${ }^{I} M$. Tech, Department of EEE, ASRA, Hyderabad, Telangana, India \\ ${ }^{2} M$. Tech from National Institute of Technology Tiruchirapalli, Tamil Nadu, India
}

\begin{abstract}
This paper proposes Particle Swarm Optimization (PSO) based approach for light intensity control in a Photo Voltaic (PV) supply fed LED lighting system. The output power regulation of LED lighting system is formulated as an optimization problem and the output power regulation is carried out using a real time PSO technique. The concept is first simulated and verified and subsequently implemented on a 16-bit PIC microcontroller. The proposed method possesses the major advantage of system independence while regulating the output power. The computed and measured results clearly illustrate the effectiveness of the new method.
\end{abstract}

Keywords: Particle Swarm Optimization, Light Emitting Diode and Photo Voltaic System etc...

\section{INTRODUCTION}

With the rapidly increasing energy demand all over the world, saving lighting energy in building environments has acquired a new research area since the lighting energy constitutes about $20 \%$ of energy consumption in commercial establishments [1]. In this context solid state LEDs are expected to play a significant role in lighting systems due to the advantages of a Light Emitting Diode (LED) include long lifetime, low maintenance requirements, improved luminance, fast response, and smaller size [2]-[5]. Therefore, LEDs have been widely used for various lighting applications, such as traffic lights, flash lights, automotive lightings, signage lights, and liquid-crystal display (LCD) television backlights [6]. The LED driver circuit is an important component in LED lighting system. The methods for LED driving are generally classified into three basic categories [7]-[9]: constant voltage control, constant current controller, and constant power control. It is well established in the literature that constant power control of LED is far superior to constant voltage control and constant current control as given in [9].

The architecture of existing LED lighting systems consists of a Photovoltaic (PV) source charging a battery and the battery is feeding the LED. This type of schematic is best suitable for applications such as night street lighting. However, there are several applications where the battery can be dispensed with and the sun light is directly converted into artificial light. This scheme is called light-to-light (LtL) conversion [10]. One typical application is high-energyefficient photo catalytic reactors [11]. One can also think of the use of LtL conversion schemes in indoor applications during day time such as air-conditioned cabins and conference halls, decorative lighting schemes in hotels and marriage halls. In all the above applications the PV can directly feed the LED system during the day time and intensity of LED illumination can be adjusted as desired.
While this scheme is simple in its perspective, the design of the feedback controller for output power regulation is a challenging task due to the following reasons: (i). The voltage-current characteristic is nonlinear. (ii). The dc-dc converter acting as interface between the PV array and the LED is also a non-linear system. With rapid change in climatic conditions such as solar insolation and ambient temperature, the PV array also possess a non-lineart characteristic.

Particle Swarm Optimization (PSO) is a stochastic optimization algorithm [12]-[16] and has simple structure, fast computation capability and can be incorporated in low cost micro controllers. Another advantage of PSO algorithm is that it is system independent when employed in real time applications.

This paper proposes the output power regulation for a light to light conversion scheme based on Particle Swarm Optimization (PSO). A boost type dc-dc converter is interfaced between the PV module and the LED and the duty ratio of the converter is identified through PSO for a typical operating point. The PSO code is downloaded to a 16-bit PIC microcontroller and is used for tracking the reference power. The measured results are given to substantiate the new method.

\section{ECONOMIC ANALYSIS}

The present trend is to replace the existing lighting system with LED lighting system. This section therefore describes the total power saved by upgrading conventional lighting technology to LED technology. For a sample test data, LED lighting is proposed in a conference hall of 9 meter by 4 meter where the conventional fluorescent lamp fixtures were used to illuminate the hall during daytime. Figure 1 shows the hall layout where 12 fluorescent lamps, each $75 \mathrm{~W}$ were used. With the existing luminaire, the lux distribution is 
shown in Figure 2. In order to obtain the same lux distribution and visual comfort, each fluorescent lamp is now replaced with LED system of $32 \mathrm{~W}$. Thus the total power saved for the conference hall is $(75-32) * 12=516 \mathrm{~W}$. Accordingly the savings obtained are computed in Tables 1 , 2 and 3.

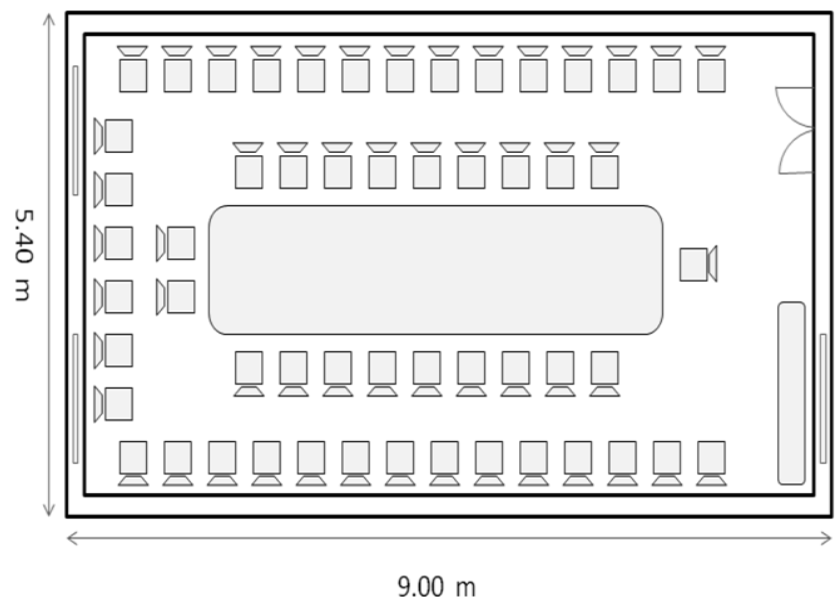

Fig.1. Hall Layout

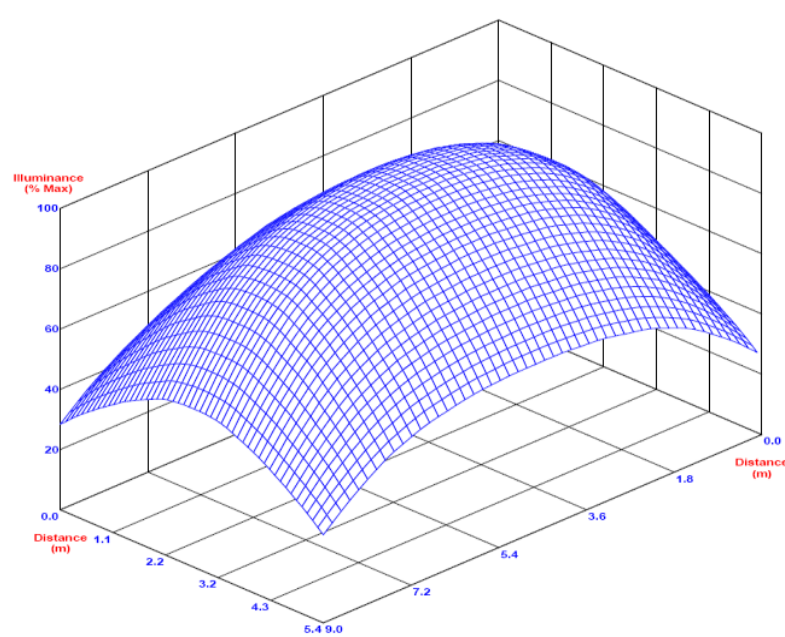

Fig.2. Lux distribution with existing luminaire

Table 1 Total energy (kilowatt hours, kWh) saved annually

\begin{tabular}{|l|l|}
\hline Total kilowatts saved & $0.516 \mathrm{~kW}$ \\
\hline Hours of use per day & $6 \mathrm{Hrs}$ \\
\hline Days of use per Week & 5 \\
\hline Weeks of use per Year & 52 \\
\hline Total kWh saved per Year & $804.96 \mathrm{kWh}$ \\
\hline
\end{tabular}

Table 2 Total energy cost savings per year

\begin{tabular}{|l|l|}
\hline Energy cost per kWh & Rs. 7 \\
\hline Energy Cost savings per year & Rs. 5634.72 \\
\hline
\end{tabular}

Table 3 Energy cost savings over the life of the LED

\begin{tabular}{|l|l|}
\hline LED life (hours) & $50000 \mathrm{Hrs}$ \\
\hline Hours per year usage & $1560 \mathrm{Hrs}$ \\
\hline LED est. life & 32.05 years \\
\hline Energy cost savings per year & Rs. 5634.72 \\
\hline Lifetime energy cost savings & Rs. $1,80,600$ \\
\hline
\end{tabular}

Table 4 Parameters of Buck Converter

\begin{tabular}{|l|l|l|}
\hline S.No. & Parameter & Value \\
\hline 1 & Inductance & $\mathrm{L}=1.812 \mathrm{mH}, \mathrm{r}_{\mathrm{L}}=0.394 \Omega$ \\
\hline 2 & Capacitance & $\mathrm{C}=100 \mu \mathrm{F}, \mathrm{r}_{\mathrm{C}}=0.3 \Omega$ \\
\hline 3 & Potential divider & $\mathrm{R} 1=2.2 \mathrm{M} \Omega ; \mathrm{R} 2=1.1 \mathrm{M} \Omega$ \\
\hline
\end{tabular}

The details of PV array are given in Table 5.

Table 5: Details of PV array

\begin{tabular}{|l|l|l|}
\hline S.No. & Parameter & Value \\
\hline 1 & Open circuit voltage, $V_{o c}(\mathrm{~V})$ & 21 \\
\hline 2 & Short circuit current, $I_{s c}(\mathrm{~A})$ & 1.3 \\
\hline 3 & Voltage at maximum power, $V_{\operatorname{mp}}(\mathrm{V})$ & 17.4 \\
\hline 4 & Current at maximum power, $I_{\operatorname{mp}}(\mathrm{A})$ & 2.4 \\
\hline 5 & Maximum power, $P_{\max }(\mathrm{W})$ & 40 \\
\hline 6 & Maximum system voltage $(\mathrm{V})$ & 600 \\
\hline 7 & Tolerance $(\%)$ & $(+/-) 3$ \\
\hline
\end{tabular}

\subsection{Payback from Energy Cost Saving}

Payback from energy savings is the ratio of LED cost or difference between LED \& original lamp and energy Cost savings per year $=($ Rs. $1500 \times 12) /$ Rs. $5634.72=3.2$ years Return on Investment $(\mathrm{ROI})=100 /$ payback $=\mathbf{3 1 . 3 5 \%}$

\section{EXPERIMENTAL SYSTEM DESCRIPTION}

The proposed LED power control scheme is given in Figure 3. It consists of a PV array, a boost converter, LED lighting system and a feedback system for output power regulation. The LED current and voltage are sampled at the rate of 100 milliseconds. A multiplier is now used to compute the LED power, $\mathrm{p}_{0}$ as in Figure 3. If there is an error between the measured power output and the reference value, the particle swarm optimization algorithm is made to run on line. The program is terminated when the displacement among the particles reaches a set minimum value. Then the dc-dc converter is activated with this optimum duty ratio.

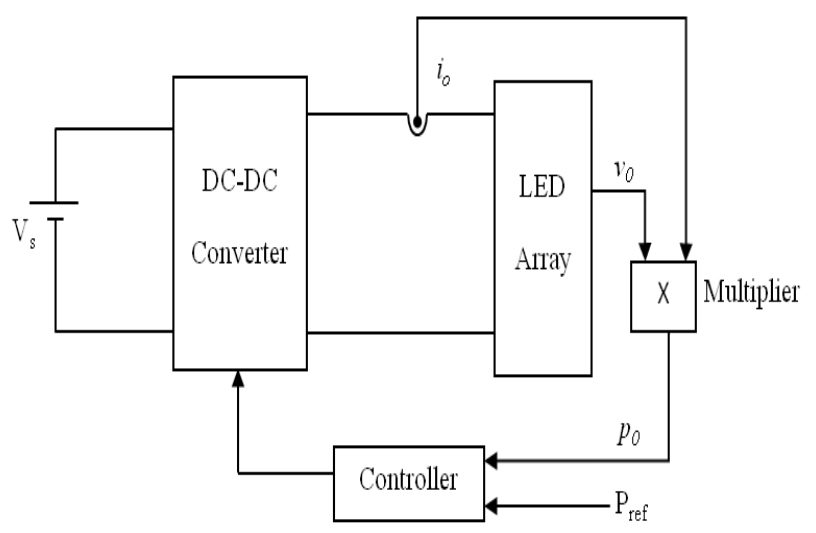

Fig.3. Constant Power Control scheme

\section{PARTICLE SWARM OPTIMIZATION}

The particle swarm optimization (PSO) algorithm belongs to the category of Swarm Intelligence methods [12-16]. PSO is a population-based algorithm that exploits a population of individuals to probe promising regions of the search space. 
In this context, the population is called a swarm and the individuals are called particles. PSO algorithm iteratively explores a multidimensional search space with a swarm of particles, looking for the global minimum (or maximum). Each particle "flies" through the search space according to its velocity vector. In every iteration, the velocity vector is adjusted so that prior best positions (cognitive aspect) and the best position found by particles within a specific neighborhood (social aspect) act as attractors. In the original PSO algorithm, the neighborhood of a particle consists of all particles, so that the global best position, i.e., the best solution found so far, directly influences its behaviour. Each particle moves with an adaptable velocity within the search space, and retains in its memory the best position it has encountered so far. In PSO, the agents are considered to have the ability to memorize the best position they have attained.

The steps of PSO technique for LED power control are given below.

1. Initialize the parameters maximum number of iterations $N$, population size $n$, acceleration parameters $c_{1}$ and $c_{2}$ and inertia weight $w$.

2. Randomly generate $n$ particles.

3. Initialize for each particle, the pbest as current location.

4. While $(i<N)$

$$
\text { 4.1. While }(j<n)
$$

4.1.1. Calculate the fitness value of the particle.

4.1.2. If current fitness of the particle is better than previous best position, update the pbest.

\subsection{3. $j=j+1$.}

4.2. If the fitness of the best particle is better than the global best position, gbest reached so far, update the global best position, gbest.

\section{3. $i=i+1$.}

5. End.

The output power control of the LED lighting system is operated as given in the flow chart in Figure 4.

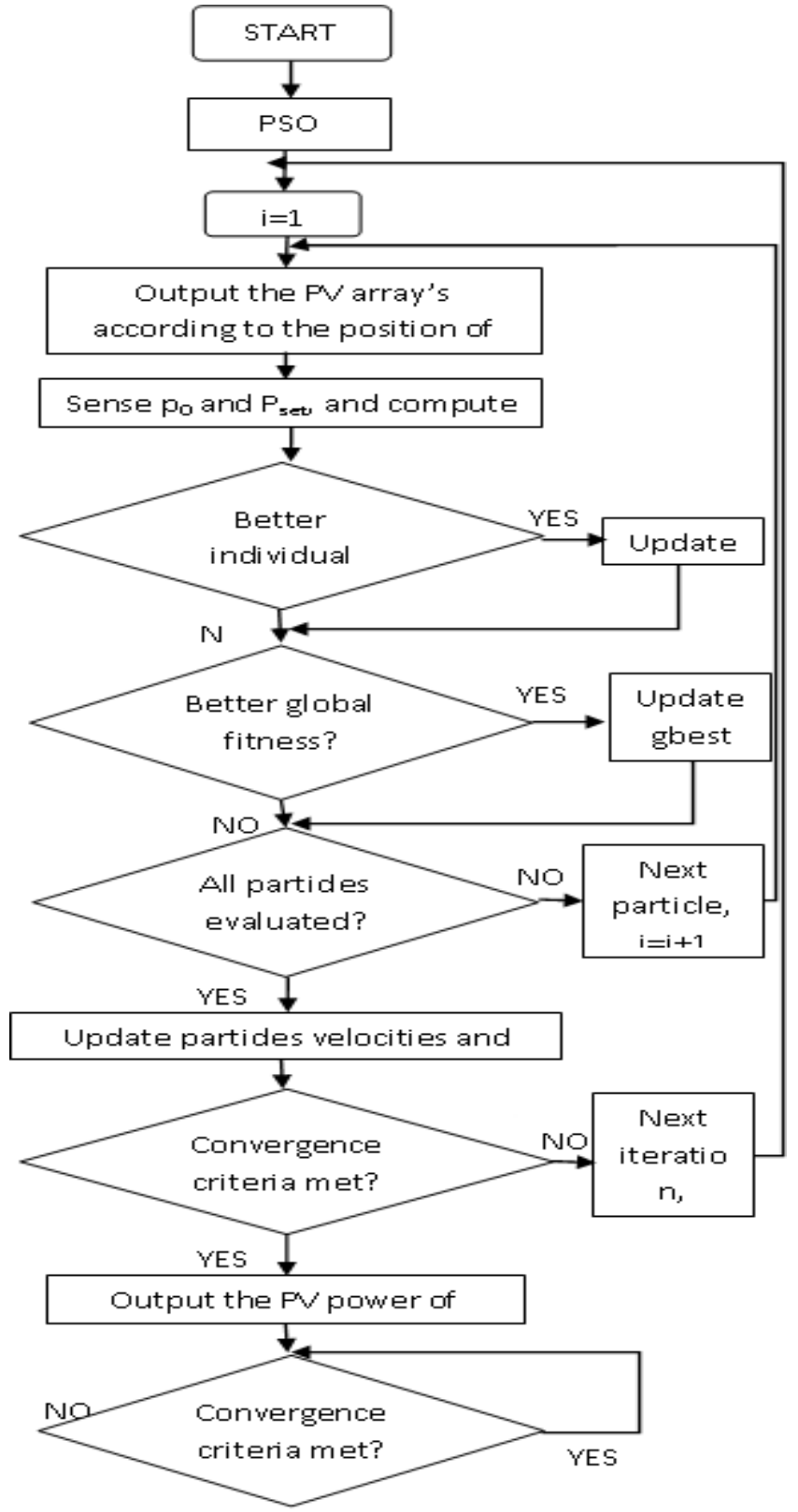

Fig.4. Flow chart

\section{PSO ALGORITHM FOR CONSTANT POWER CONTROLLER}

This section explains the implementation of Particle Swarm Optimization (PSO) based algorithm for regulating PV fed LED output power. A boost type dc-dc converter is used as the power converter and PIC microcontroller is used to generate pulses for the converter. The circuit diagram of constant power control scheme for Photo Voltaic (PV) array fed LED is shown in Fig. 3. It employs a PV array as source, a boost converter comprising a power electronic switch such as IGBT, a power diode, an inductor, and a capacitor, a current sensor to sense the current flowing through the LED array, a potential divider to sense the voltage across the LED array, a multiplier to get the product of voltage across and current through the LED array, and a microcontroller to generate pulses to the boost converter. 


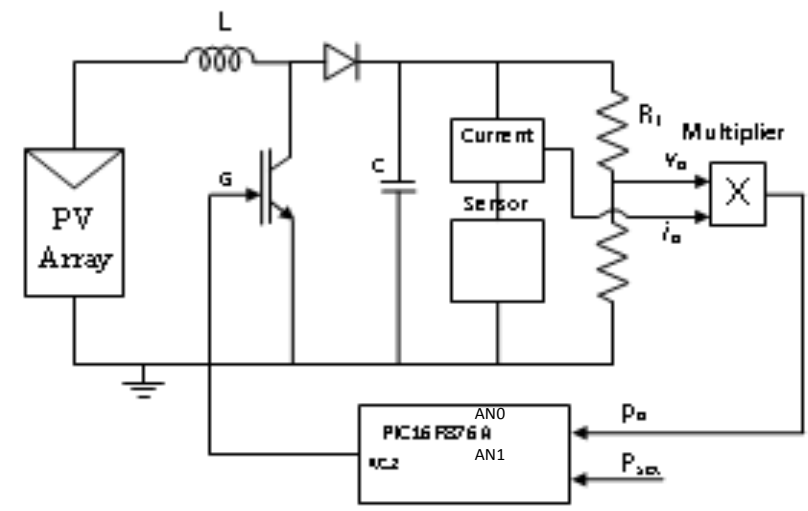

Fig.5. Constant power controller using PSO

The output voltage across the LED array is measured and is given as one of the inputs to multiplier IC through the potential divider forming with $\mathrm{R}_{1}$ and $\mathrm{R}_{2}$. The other input to the multiplier IC is the current flowing though the LED array. Now, the multiplier IC gives the output power $\left(\mathrm{p}_{0}\right)$ of the LED array which is given to the microcontroller. To set the required power, i.e., set power $\left(\mathrm{P}_{\text {set }}\right)$ is also given in terms of voltage to the microcontroller which uses particle swarm optimization (PSO) algorithm to process and gives pulses to the boost converter to maintain constant power to the LED array. The PIC16F876A microcontroller is used for producing firing pulses to the boost converter. This IC is available in 28-pin package. This device has three I/O ports and five $A / D$ input channels and $A / D$ conversion module is in-built.

A dedicated program for particle swarm optimisation based power regulation is developed in MPLAB and then downloaded to the PIC microcontroller for the closed loop operation. The experimental results are explained in the following section.

\section{EXPERIMENTAL RESULTS}

The PV array fed LED lighting system was fabricated in the laboratory. The specifications of the experimental system are given in Table 4. Experiments were conducted at different operating points of the LED lighting system. Figure 6(a) shows the output power response of the system for a step input of amplitude $12 \mathrm{~W}$. It is seen that the power output oscillates evidently due to random initial positions of the particles. As the iteration proceeds, the particles do come closer to each other and the PSO algorithm is terminated when the position of the best particle corresponds to the reference value of $12 \mathrm{~W}$. The response time is approximately 5 seconds.

After 20 seconds, the reference power is now increased to $24 \mathrm{~W}$. The microcontroller senses the reference value and the PSO algorithm is re-started again. It is seen that the power output oscillates but settles to the reference value less than 5 seconds. The experimental results given in Figure 6(a) clearly illustrate the tracking capability of the proposed algorithm.
During day time the solar insolation as well as ambient temperature will change due to environmental changes: sometimes these changes may be drastic such as a cloudy day or a very hot day in summer. The proposed controller must maintain the required power level in the conference hall for the efficiency of the working staff inside the conference hall. In order to test the controller with solar insolation change, artificial shading of the solar panel is now performed and this is shown in Figure 6(b) with reduced solar insolation the LED output power comes down forcing the microcontroller to initialise the PSO algorithm. As can be seen from Figure 6(b), the algorithm effectively identifies the new duty ratio so as to meet the reference power with decreased insolation. The search time is observed to be 5 seconds within which the dc-dc converter regulates the output power to $12 \mathrm{~W}$. The artificial shading is now removed increasing the solar insolation. This increases the output power from the PV array and hence the PSO algorithm is started once again to regulate the output power. The required regulation time is around 5 seconds. The performance curves in Figure 6(b) illustrate the robust nature of the PSO algorithm in rejecting external as well as internal disturbances.

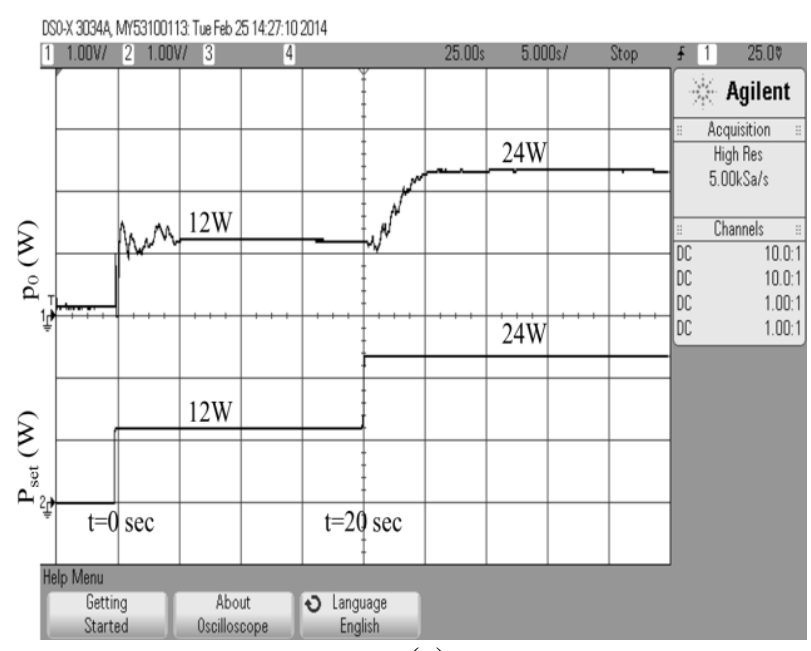

(a)

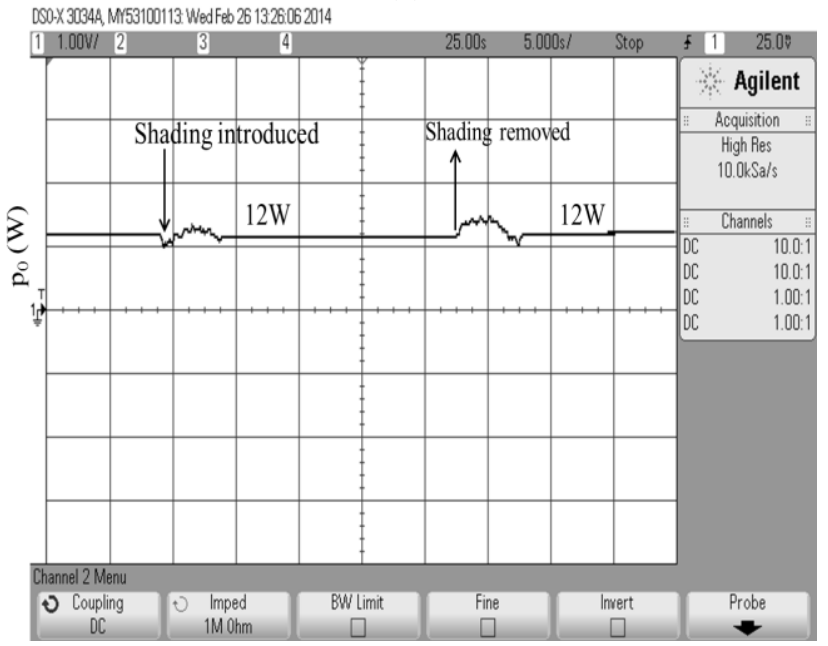

(b)

Fig.6. Experimental Results 


\section{CONCLUSION}

This paper has illustrated a new method of output power regulation in LED lighting systems employing Particle Swarm Optimization approach. The proposed method is simple to implement and is also system independent. The measured results for different types of internal as well as external disturbances clearly illustrate that the proposed algorithm is robust and immune to various disturbances.

\section{REFERENCES}

[1]. M. S. Shur and A. Zukauskas, "Sokid-state lighting: Toward superior illumination," Proc. IEEE, vol. 93, no. 10, pp. 1691-1703, Oct. 2005.

[2]. H.J. Chiu and S.J. Cheng, "LED backlight driving system for large-scale LCD panels," IEEE Trans. Ind. Electron., vol. 54, no. 5, pp. 2751-2760, Oct. 2007.

[3]. N. Narendran and Y. Gu, "Life of LED-based white light sources,” J. Display Technol., vol. 1, no. 1, pp. 167171, Sep. 2005.

[4]. I. Hino and K. Iwamoto, "LED pulse response analysis considering the distributed $\mathrm{CR}$ constant in the peripheral junction," IEEE Trans. Electron. Devices, vol. ED-26, no. 8, pp. 1238-1242, Aug. 1979.

[5]. S. D. Lester, M. J. Ludowise, K. P. Killeenm, B. H. Perez, J. N. Miller, and S. J. Rosner, "High-efficiency InGaN MQW blue and green LEDs," J. Cryst. Growth, vol.189/190, pp. 786-789, Jun. 1998.

[6]. H. J. Chiu, Y. K. Lo, T. P. Lee, S. C. Mou, and H. M. Huang, "Design of an RGB backlight circuit for liquid crystal display panels," IEEE Trans. Ind. Electron., vol. 56, no. 7, pp. 2793-2795, Jul. 2009.

[7]. G. Carrato, "Solving high-voltage off-line HB-LED constant-current control circuit issues," in Proc. IEEE Appl. Power Electron. Conf. (APEC), 2007, pp. 1316-1318.

[8]. Y. Hu, and M. M. Jovanovic, "LED driver with selfadaptive drive voltage," IEEE Trans. Power Electron., vol. 23, no. 6, Nov. 2008.

[9]. B. J. Huang, C. W. Chen, P. C. Hsu, W. M. Tseng, and M. S. Wu, "Direct battery-driven solar LED lighting using constant-power control," Solar Energy, 86 (2012), pp. 32503259 .

[10]. Femina, N., Fortunato N., Vitelli, M., "Light to Light, PV fed lighting systems," IEEE trans. Power Electronics, Vol.28, Iss.8 (2013), pp. 4063-4073.

[11]. D. H. Chen, X. Ye and K. Li "Oxidation of PCE with a UV LED photocatalyst reactor", Chem. Eng. Tech., vol. 28, no. 1, pp.95-97 2005

[12]. J. Kennedy, and R. Eberhart, "Particle Swarm Optimization," in Proc. of the IEEE Int. Conf. on Neural Networks, Pisctaway, NJ, pp. 90-97.

[13]. H. Xiaohui, S. Yuhui, and R. Eberhart, "Recent advances in particle swarm," in Proc. Congr. Evolut. Comput., 2004, vol. 1, pp. 90-97.

[14]. Y. Shi, and R. Eberhart, "A modified particle swarm optimizer," in Proc. IEEE World Congr. Comput. Intell., Piscataway, NJ, pp. 69-73, 1998.

[15]. A. Ratanaweera, Saman K. Halgamuge, Hary C.

Watson, "Self organizing hierarchical particle swarm optimizer with time-varying acceleration coefficients," IEEE Trans. Evol. Comput., vol. 8, no. 3, Jun. 2004.

[16]. P. N. Suganthan, "Particle swarm optimizer with neighbourhood operator," Proc. Evol. Comp., 1999.

[17]. J. Robinson, Y. Rahamat Samii, "Particle Swarm Optimization in electromagnetics," IEEE Trans. Antennas and Propagation, vol. 52, no. 2, pp. 397-407, Feb. 2004. 